\section{Tumori uterusa}

\section{Svetlana Milenković}

Ginekološko akušerska klinika Višegradska, Klinički centar Srbije, Beograd, Srbija

\section{Apstrakt}

Poslednja revizija klasifikacije tumora uterusa uradjena je 2003.godine. Prema WHO, karcinomi endometrijuma podeljeni su u dve grupe, nazvane tip I i tip II. Tip I - grupa endometrioidnih adenokarcinoma, ima veću učestalost. Serozni i svetloćelijski adenokarcinom su u grupi II, po definiciji su karcinomi visokog gradusa, loše prognoze, bez jasno definisanih prekursora i predisponirajućih faktora rizika. U tipu I postoji PTEN mutacija, a u tipu II prekomerna ekspresija p53, pa se ova dva biomarkera koriste u njihovoj diferencijalnoj dijagnozi.WHO je definisala trostepeni sistem u odredjivanju gradusa endometrioidnih adenokarcinoma u kome skvamozna komponenta tumora nema uticaja. Postoje i drugi, dvostepeni, načini gradiranja ovih tumora, ali nisu opšteprihvaćeni. U odredjivanju stadijuma tumora važeća je FIGO klasifikacija 2009. u kome se tumori ograničeni na telo uterusa dele na stadijum IA i IB.U grupi mezenhimalnih tumora izdvojen je nediferentovani sarkom, koji se svojom morfologijom i imunohistohemijski razlikuje od leiomiosarkoma i endometrijalnog stromalnog sarkoma. Prihvaćeni su i novi termini kao što je UTROSCT, ali i nova teorija o nastanku karcinosarkoma. Smatra se da ovi tumori imaju epitelno poreklo, zbog čega sarkomska komponenta pokazuje pozitivnost i na epitelne i na mezenhimne markere.Otkriven je i veliki broj novih antitela, koja u dijagnostici i diferencijalnoj dijagnostici tumora uterusa imaju značaja samo ako se koriste u korelaciji sa morfološkom slikom i kliničkim podacima (karcinom endometrijuma vs karcinom jajnika, adenosarkom vs adenofibrom).

\section{Tumors of the uterus}

Svetlana Milenkovic

Gynecology and Obstetrics Clinic Visegradska, Clinical Center of Serbia, Belgrade, Serbia

\section{Abstract}

The latest version of uterine tumors classification was done in 2003. According to WHO classification, endometrial cancers are divided into two groups, so called Type I and Type II. Endometrioid adenocarcinoma has a higher frequency and belongs to Type I. Serous and clear-cell adenocarcinoma, are forming Type II and by definition, they are high grade cancers with poor prognosis and no clearly defined precursors and predisposing risk factors. In Type I, there is a PTEN mutation and in Type II overexpression of p53. These two biomarkers are used in their differential diagnosis. WHO has defined a three-step system in determining the grade of endometrioid adenocarcinoma in which squamous component has no significance. There are other, two-step, grading systems which are not generally accepted.2009 FIGO classification is still in use for tumor staging and according to that tumors confined to the uterus body are divided into stages IA and IB.

In the group of mesenchyme tumors, undifferentiated sarcoma was separated, due to different morphology and immunohistochemical profile compared to leiomyoma and endometrial stromal sarcoma. New terms, like UTROSCT, are accepted as well as new theory about the origin of carcinosarcoma. Common believe is that these tumors have epithelial origin and therefore sarcoma component showed positivity on epithelial and mesenchymal markers too.

Large number of new antibodies was discovered which in the diagnosis and differential diagnosis of uterine tumors are only meaningful when used in correlation with the clinical picture and morphological data (endometrial carcinoma vs. ovarian carcinoma, adenosarcoma vs. adenofibroma).

\title{
Uvod
}

Endometrijalni karcinom je najčešći invazivni tumor ženskog genitalnog trakta u razvijenim zemljama sveta, a peti po učestalosti maligni tumor žena uopšte. Dva puta češće oboljevaju pripadnice bele rase, ali je smrtnost veća kod Crnkinja verovatno kao posledica lošeg kvaliteta zdravstvene zaštite i/ili genetskih razloga.

Na osnovu kliničkopatološke slike i molekularno genetskih promena, karcinomi endometrijuma su podeljeni u dva tipa, jednostavno nazvanih Tip I i Tip II. 
Tip I: 90\% slučajeva endometrijalnih karcinoma pripada ovoj grupi. Javlja se kod premenopauzalnih i perimenopauzalnih žena, uslovljen je hroničnom estrogenom stimulacijom, a vodeći rizični faktori za njegov nastanak su: ovarijalna disfunkcija, gojaznost, dijabetes i nuliparitet. Najčešće su dobro diferentovani, simulirajući u histološkoj slici normalne endometrijalne žlezde, pa se zbog toga nazivaju endometrioidni adenokarcinomi. Imaju dobru prognozu, a prihvaćeni patogenetski put njihovog nastanka je sledeći: povećani nivo estrogena $\rightarrow$ anovulatorni endometrijum $\rightarrow$ atipična hiperplazija (EIN) $\rightarrow$ adenokarcinom. Pretpostavka je da je potrebno da protekne 3 do 5 godina za transformaciju od atipične hiperplazije do adenokarcinoma.

Tip II: Manje učestali tip karcinoma, od koga oboljevaju žene u sedmoj i osmoj deceniji života. Prognostički su lošiji od prve grupe tumora, nisu uslovljeni hiperestrinizmom, dijabetesom niti gojaznošću, a razvijaju se na terenu atrofičnog endometrijuma. Ovoj grupi pripadaju serozni i svetlo ćelijski tip adenokarcinoma.

\begin{tabular}{|l|l|l|}
\hline Parametar & Tip I & Tip II \\
\hline Starost & $50-60$ godina & $70-80$ godina \\
\hline Gojaznost/hiperestrinizam & Česta & neuobičajena \\
\hline Endometrijum & Anovulatorni & Atrofični \\
\hline Prekursorna promena & Atipična hiperplazija (EIN) & Nepoznat (EIS?) \\
\hline Transformacija & Spora & Brza \\
\hline Tip karcinoma & Endometrioidni & Serozni ili svetloćelijski \\
\hline Molekularna promena & MSI, PTEN mutacija & p53 mutacija \\
\hline Familijarni sindrom & HNPCC & \\
\hline Način širenja & Limfni nodusi & peritoneum \\
\hline Zahvatanje jajnika & Često & Retko \\
\hline Prognoza & Dobra & Loša \\
\hline
\end{tabular}

Tabela 1. Sumirane karakteristike karcinoma endometrijuma tipa I i II

\section{Tip I - Endometrioidni adenokarcinom ${ }^{1}$}

Mikroskopski nalaz: maligne žlezdane strukture koje odgovaraju normalnom proliferativnom endometrijumu, ali se od njega razlikuju kribriformnim rastom, viloglandularnim strukturama, većom nuklearnom atipijom nego u slučaju atipične hiperplazije, kao i oskudnom ili čak otsutnom stromom izmedju. Epitel je najčešće pseudostratifikovan, bazalno orjentisanih uniformnih jedara.Retko, i žlezdane strukture mogu biti izrazito ujednačene, tubularne, stvarajući sliku koja odgovara Sertoli ćelijskom tumoru jajnika. Često su prisutni i penušavi histiociti u stromi, što po nekim autorima ukazuje na primarno endometrijalno pre nego na cervikalno poreklo tumora, ukoliko postoji diferencijalno dijagnostička dilema. Vrlo bitna karakteristika ove grupe karcinoma je i skvamozna diferencijacija, koja stepenom atipije može varirati: a) diskretna gnezda - morule uniformnih nekeratinizirajućih skvamoznih ćelija koja se obično vide kod EIN ili metaplazije, b)manja polja čak i bizarne skvamozne diferencijacije sa prominentnom keratinizacijom i nuklearnom atipijom obično udružena sa slabo diferentovanim tumorom i c) manje upadljiva područja skvamozne diferencijacije sa fokalnom keratinizacijom i većim nuklearnim gradusom koja se teško mogu razlikovati od skvamocelularnog karcinoma i obično su udružena sa slabo diferentovanim endometrioidnim adenokarcinom.

Prognostički značaj skvamozne diferencijacije nekada je bio predmet rasprave, ali se danas smatra da na prognozu utiče samo stepen diferencijacije žlezdane komponente, pa su termini ,,adenoakantom“ i ,,adenoskvamozni“ karcinom napušteni, a prihvaćen je termin „endometrioidni adenokarcinoma sa skvamoznom diferencijacijom“. Pored ovog tipa, u grupi endometrioidnog adenokarcinoma svrstane sudrugi, redji podtipovi ${ }^{2} \mathrm{sa}$ 1) mucinoznom 2) tubalnom (cilijarnom) 3) sekretornom 4)skvamoznom(tranziciocelularnom) diferencijacijom, kao i 5)viloglandularni tip.

Mucinozna diferencijacija: često je prisutna kao minor komponenta uobičajenog tipa endometrioidnog adenokarcinoma i definiše se prisustvom veće količine intracelularnog mucina. Svojom histološkom gradjom odgovara endocervikalnom tipu žlezda, ali se mnogo češće sreće u endometrijalnim nego endocervikalnim karcinomima. U retkim slučajevima može se uočiti gastrična ili intestinalna diferencijacija karcinomskih ćelija. 
Tubalna diferencijacija: tubalna diferencijacija je uobičajena i u benignom i u maligno izmenjenom endometrijumu. Termin se koristi u slučajevima veoma izraženog prisustva cilija na površini karcinomskih ćelija i po definiciji, ovaj karcinom pripada grupi dobro diferentovanih tumora.

Sekretorna diferencijacija: retka je i karakteriše se prisustvom bazalnih ili supranuklearnih vakuola slično rano sekretornoj fazi, ali su žlezde veće, nepravilnije, sa pregradjivanjem lumena.

Viloglandularni karcinom: dominantna histološka slika su brojne razgranate papile diskretne vezivno tkivne strome, obložene pseudostratifikovanim endometrioidnim epitelom. U većem broju endometrioidnih adenokarcinoma (čak i do 30\%) može se uočiti izvestan stepen viloglandularne gradje, ali je u samo manje od 5\%slučajeva dominantan mikroskopski nalaz. Postoje izvesna neslaganja oko prognostičkog značaja ove karcinomske forme u zavisnosti od studije, ali se misli da nema bitne razlike u odnosu na uobičajeni tip diferencijacije.

\begin{tabular}{|ll|}
\hline \multicolumn{2}{|l|}{ FIGO sistem odredjivanja histološkog gradusa } \\
\hline Gradus 1 & Manje od 5\% tumora su područja solidne gradje \\
\hline Gradus 2 & Područja solidne gradje obuhvataju $5-50 \%$ tumora \\
\hline Gradus 3 & Područja solidne gradje obuhvataju preko $50 \%$ tumora \\
\hline $\begin{array}{l}\text { Napomena: izražena nuklearna atipija povećava gradus tumora za jedan stepen, a prisustvo skvamozne } \\
\text { diferencijacije ne utiče na gradus tumora }\end{array}$ \\
\hline
\end{tabular}

Tabela 2. Histološki gradus endometrioidnih adenokarcinoma

Postoje i drugi predloženi načini odredjivanja stepena diferencijacije, jer se kao najveći nedostatak FIGO sistema ističe problem pri odredjivanju donje predložene granice $-5 \%$ solidnog rasta izmedju gradusa 1 i 2 , kao i mala razlika u prognozi izmedju njih ( $92 \%$ vs $88 \%$ 5-godišnjeg preživljavanja).

Taylor i saradnici predlažu binarni sistem u kojima kod gradusa 2 tumor pokazuje više od $20 \%$ solidnog rasta, što daje veću reproducibilnost u odnosu na trostepeni sistem ( $\kappa 0,97$ vs 0,53 ).

Lax i saradnici ${ }^{3}$ takodjesugerišu binarni sistem u kojima o gradusu 2 tumora odlučuju prisutna dva ili više parametra od sledećih predloženih: (1) više od 50\% tumora je solidnog načina rasta (nema uticaja da li se o radi o skvamoznim ili neskvamoznim poljima), (2)difuzno infiltrativna vs ekspanzivna miometrijalna invazija (3) tumorska nekroza. Za tumore koji su ograničenina endometrijum, 50\% ili više solidnih polja i tumorska nekroza odredjuju visoki gradus tumora.U njihovoj analizi postignuta je visoka korelacija u odnosu na 5-godišnje preživljavanje, ali se kao osnovni nedostatak ističe primenjivost samo na već operisane pacijente, jer je važan kriterijum način miometrijalne invazije.

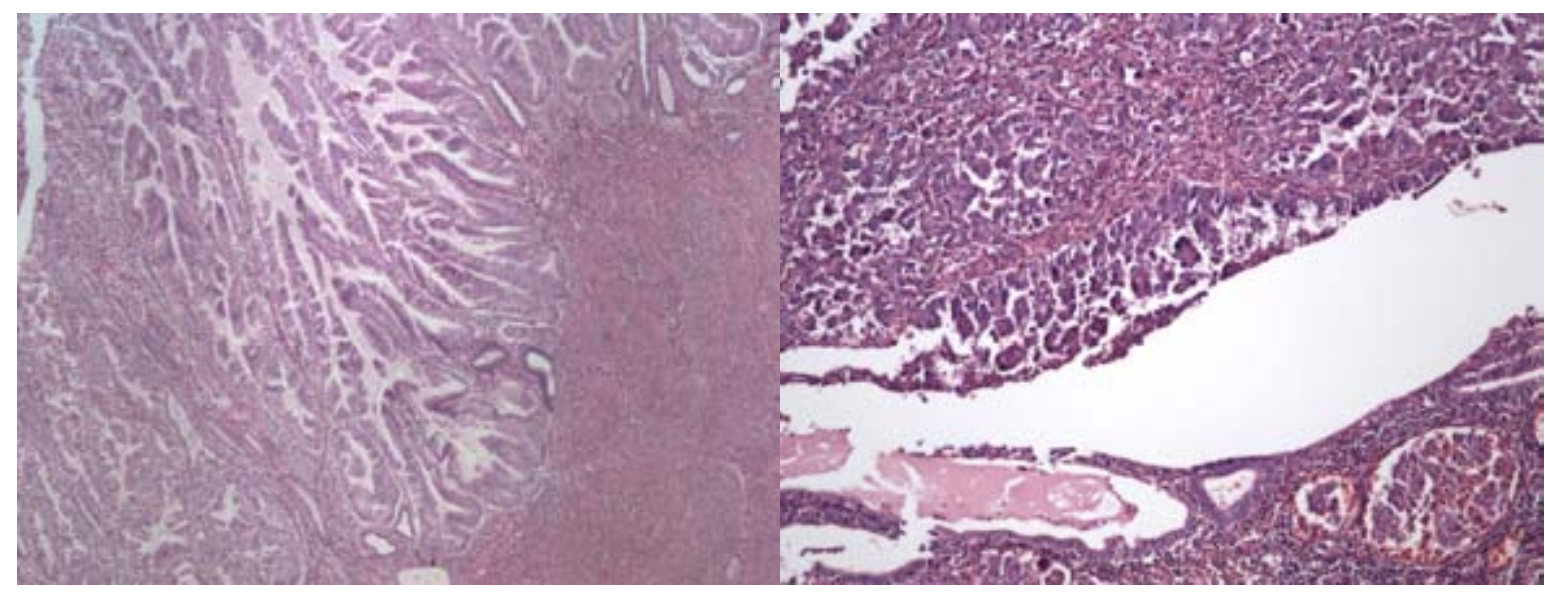

Endometrioidni adenokarcinom Serozni adenokarcinom

Slika 1. Histološki tipovi carcinoma endometrijuma 
Imunohistohemijski profil: Endometrioidni adenokarcinomi pokazuju ekspresiju pan-citokeratina, EMA, CA125, dok je ekspresija CEA neuobičajena. Skoro svi su CK7 pozitivni i CK 20 negativni, a mucinozna varijanta je nekada CDX2 pozitivna. Za razliku od ostalih karcinoma, endometrioidni su izrazito vimentin pozitivni. FIGO gradus I i II tumora ispoljavaju pozitivnost za ER i PR kao i oko polovine slučajeva gradusa 3.p53 ekspresija nije uobičajena u gradusu 1 i samo je minimalno izražena u gradusu 2, ali je prisutna u velikom broju slučajeva gradusa 3. Manji panel imunohistohemijskih markera može biti koristan u diferencijalnoj dijagnozi izmedju primarnih endometrijalnih i endocervikalnih karcinoma: p16fokalno+/ER+/PR+ je profil endometrijalnih, dok se p16difuzno+/ER-/PR- sreće u endocervikalnim tumorima.

\section{Tip II}

Ovoj grupi pripadaju dva tipa endometrijalnog karcinoma: serozni (sinonim serozni papilarni adenokarcinom) i svetloćelijski (clear cell) adenokarcinom. Po definiciji, oba tipa tumora pripadaju karcinomima visokog stepena maligniteta i ne gradiraju se.

\section{Serozni (papilarni) adenokarcinom}

Entitet koji se izdvaja u poslednjih 20-tak godina, javlja se sa učestalošću manjom od 10\% (u nekim studijama oko 1,1\%),prepoznat u nekoj od sledećih formi, koje se uzajamno ne isključuju: (1) mešoviti serozni i endometrioidni adenokarcinom (2)serozni adenokarcinom u polipu (3)serozni karcinom ograničen na endometrijalnu površinu (tzv.intraepitelni karcinom).

Mikroskopska slika: papilarne strukture koje mogu biti velike, široke, nepravilne, obložene tumorskim ćelijama sa visokim jedarno/citoplazmatskim odnosom su jedna od karakterističnih nalaza. Drugi tip promene je udružen sa prethodnim i odnosi se na eksfolijaciju karcinomskih ćelija sa površine papila (mikropapilarni rast). Treći način rasta je prisustvo mikropapila unutar žlezdanih struktura. U 30-40\% slučajeva prisutna su psamoma tela.

Imunohistohemijskiprofil ${ }^{4}$ : oko $75 \%$ seroznih adenokarcinoma pokazuju p53 ekspresiju, Ki-67 indeks je izrazito visok (čak 50-75\%), a difuzno jaka pozitivnost postoji i za p16. Istovremeno postoji difuzni gubitak ekspresije za ER i PR, ali kao endometrioidni adenokarcinomi obično pokazuju pozitivnost za pan citokeratin, EMA, CA 125, CK 7 i vimentin i gubitak ekspresije CEA. WT1 pozitivnost je prisutna u najviše 20$30 \%$ slučajeva, što je bitno razlikuje od primarno ovarijalne, tubalne ili peritonealne lokalizacije gde je WT1 pozitivnost prisutna u najmanje $70-80 \%$ slučajeva.

\section{Svetloćelijski (clear cell) adenokarcinom}

Mikroskopska slika: solidna polja, tubulocistične ili papilarne strukture sagradjene od svetlih, glikogenom bogatih, ili „hobnail“ ćelija, izrazito atipičnih, bizarnih jedara, sa često prisutnim PAS pozitivnim, dijastaza rezistentnim eozinofilnim intracelularnim i ekstracelularnim hijalinim globulama.

\section{Mešoviti adenokarcinomi}

Mešavina tipa I (endometrioidni/mucinozni) i tipa II (serozni/svetloćelijski) karcinoma u kome je manja komponenta zastupljena sa najmanje 10\% ukupnog volumena tumora naziva se mešovitim adenokarcinom.

\section{Nediferentovani karcinom}

Ovaj tumor se izdvaja kao poseban entitet po svojoj histološkoj slici u kojoj postoji potpuni gubitak bilo kakvog tipa diferencijacije karcinomskih ćelija. Treba ga razlikovati odendometrioidnog adenokarcinoma gradusa 3 u kojem postoje očuvani bar minimalni delovi žlezdane diferencijacije, skvamozne metaplazije ili eventualne trabekularne gradje.

\section{MEZENHIMALNI TUMORI}

\section{Endometrijalni stromalni nodul}

Definicija: Jasno ograničeni tumor sagradjen od stromalnih ćelija koje odgovaraju stromalnim endometrijalnim ćelijama proliferativne faze. Izmedju njih se uočavaju brojni sitni krvni sudovi arteriolarnog tipa. Retko se mogu uočiti prstolike projekcije u miometrijum, ali ne smeju bitidubljeod $3 \mathrm{~mm}^{5}$.

Diferencijalna dijagnoza: (1)celularni leiomiom (jako pozitivna reakcija za desmin, h-caldesmon i negativna reakcija za CD 10) i (2) endometrijalni stromalni sarkom niskog stepena maligniteta (bazira se na evaluaciji miometrijalne infiltracije i zato se ne može postaviti definitivna dijagnoza na kiretaži!)

\section{Endometrijalni stromalni sarkom (ESS)}


Učestalost ovog tipa tumora je oko $0,2 \%$ od svih genitalnih malignih tumora žene.

Mikroskopska slika: hipercelularni tumor sagradjen od uniformnih ćelija tipa endometrijalnih stromalnih ćelija sa brojnim malim arteriolama koje odgovaraju spiralnim u kasno sekretornom endometrijumu. Izražena je invazija limfatika, mitotska aktivnost obično je niska (manje od 10 mitoza na 10HPF), a nekroza otsutna.U nekim slučajevima naglašena je i perivaskularna hijalinizacija.

Endometrijalni stromalni tumori mogu dodatno pokazivati i druge, različite tipove diferencijacije kao što su: glatko mišićna, obično fokalna i manja od 30\%. Ako je prisustvo ove druge komponente veće od 30\% tumor se naziva mešovitim endometrijalnim stromalnim i glatkomišićnimtumorom ${ }^{6}$. Takodje, mogu biti prisutni i elementipolnihtrakajajnika, najčešće u formi anastomozirajućih trabekula ili traka, retko tubula. Ukoliko predominiraju (pozitivnost na Inhibin!) tumor se naziva ,uterine tumor resembling ovarian sex cord stromal tumor“. Treća varijanta je prisustvo endometrijalnih žlezda koje se sreću u 10-40\% slučajeva.

Napomena: Drugi tipovi diferencijacije mogu se javiti i kod endometrijalnih stromalnih nodula kao i kod endometrijalnih stromalnih sarkoma, niskog stepena maligniteta, pa se kao diferencijalno dijagnostički kriterijum uzima miometrijalna infiltracija.

Diferencijalna dijagnoza: pored stromalnog nodula, uključuje i celularni leiomiom, intravensku leiomiomatozu kao i adenomiozu.

\section{Nediferentovani endometrijalni sarkom}

Uterini mezenhimalni tumor viskog stepena maligniteta koji ne pokazuje specifičnu diferencijaciju, ćelijska i nuklearna atipija su veoma izražene, gubi se karakterističan način rasta i vaskularnost ESS niskog stepena maligniteta, izraženo je krvavljenje i nekroza a tumorske ćelije jako liče na sarkomsku komponentu karcinosarkoma, koga je neophodno diferencijalno dijagnostički isključiti. Uopšteno, dijagnoza ovog tipa tumora uglavnom se zasniva na sekvencijalnoj eliminaciji slabo diferentovanog karcinoma, leiomiosarkoma i karcinosarkoma (od formiranja većeg broja uzoraka za analizu do korišćenja imunohistohemijskih metoda).

\section{Leiomioma}

Mikroskopska slika: Anastomozirajuće trake uniformnih, fuziformnih - vretenastih ćelija, nejasnih granica, izduženih jedara, uobičajeno retkih mitoza.

Kod trudnica ili žena koje koriste progesteronsku terapiju krvavljenje, nekroza, edem, miksoidne promene i hipercelularnost se mogu javiti i kod leiomioma.

\begin{tabular}{|c|c|}
\hline Patološka dijagnoza & Karakteristična histološka slika \\
\hline Leiomioma sa povećanom mitotskom aktivnošću & 5-10 mitoza/10HPF \\
\hline Atipični leiomioma & $\begin{array}{l}\text { Pleomorfne džinovske tumorske ćelije sa } \\
\text { naglašenom nuklearnom atipijom }\end{array}$ \\
\hline Celularni leiomiom & Značajno veća celularnost nego uobičajeno \\
\hline Epitelioidni leiomiom & $\begin{array}{l}\text { Okruglaste/ovalne/poligonalne ćelije koje } \\
\text { odgovaraju epitelnim }\end{array}$ \\
\hline Lipoleiomioma & Veći procenat zrelog masnog tkiva \\
\hline Neurilemmoma-like leiomioma & $\begin{array}{l}\text { Naglašeno nuklearno palisadanje koje odgovara } \\
\text { benignim tumorima perifernih nervnih omotača }\end{array}$ \\
\hline Intravaskularna leiomiomatoza & „Crvoliki“ intravenski benigni glatkomišićni tumori \\
\hline Diseminovana peritonealna leiomiomatoza & $\begin{array}{l}\text { Histološki benigne, tumorolike glatkomišćne lezije } \\
\text { na peritoneumu ili omentumu }\end{array}$ \\
\hline Benigni metastazirajući leiomiom & $\begin{array}{l}\text { Histološki benigne glatkomišićne mase u plućima } \\
\text { koje se tumače kao metastaze primarno uterinih } \\
\text { leiomioma }\end{array}$ \\
\hline
\end{tabular}

Tabela br.3. Histološke varijante leiomioma ${ }^{7}$ 


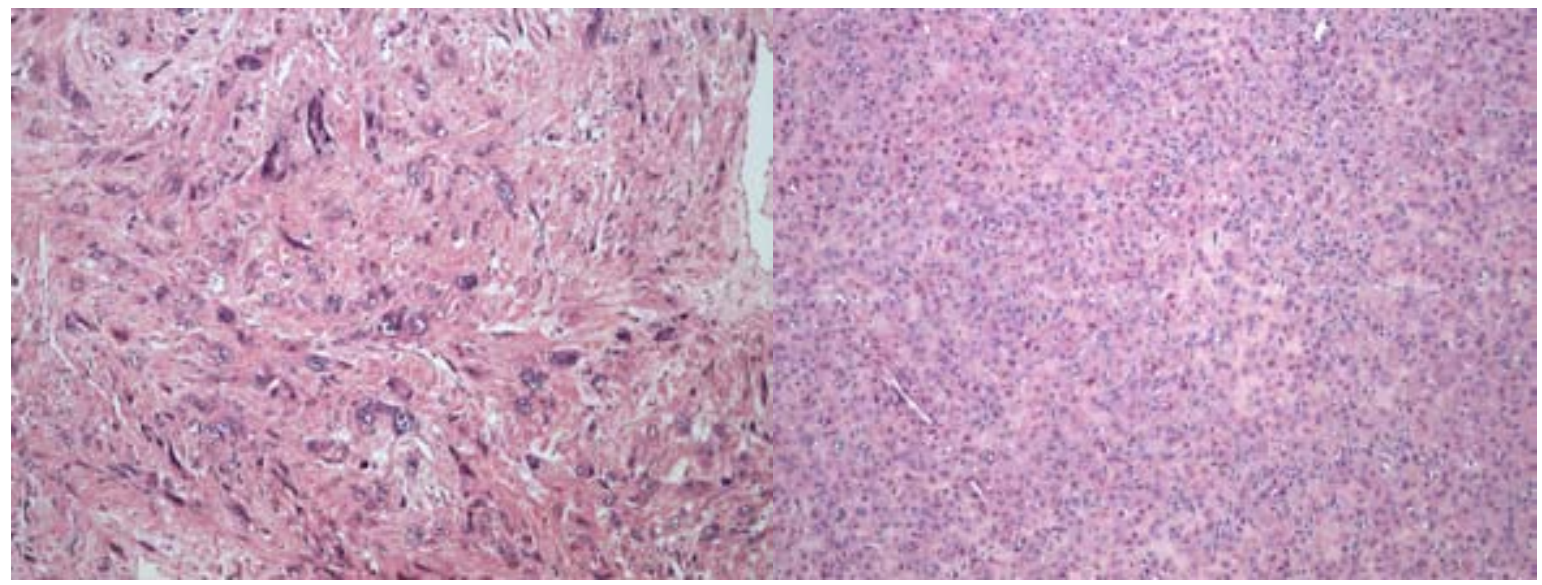

Atipični leiomiom Epiteloidni leiomiom

Slika 2. Histološke varijante lejomioma

\section{Leiomiosarkoma}

Mikroskopska slika: fascikule vretenatastih mezenhimalnih ćelija sa hiperhromatičnim jedrima, zgrudvanim hromatinom, prominentnim nukleolusima, naglašenom tumorskom nekrozom (koja nije uvek prisutna). Celularnost visoka, mitotske figure brojne, najčešće više od 15/10HPF, a vaskularna invazija prisutna u $25 \%$ slučajeva.

Kriterijumi za dijagnozu leiomiosarkoma (WHO 2003.)

1.koagulativna ćelijska nekroza

2.U odsustvu nekroze mora postojati difuzna, umerena do naglašena citološka atipija, a broj mitoza najmanje 10/10HPF.

\section{Epiteloidna varijanta leiomiosarkoma}

Mikroskopski nalaz: Hipercelularan tumor, „epiteloidnog“ fenotipa tumorskih ćelija, sa naglašenom citološkom atipijom, tumorskom nekrozom i visokim mitotskim indeksom ${ }^{8}$. Ukoliko nema nekroze, dijagnoza epiteloidnog leiomiosarkoma zahteva difuznu, umerenu do veoma izraženu citološku atipiju i 5 ili više mitoza na $10 \mathrm{HPF}$.

\section{Miksoidna varijanta leiomiosarkoma}

Mikroskopski nalaz: Tumorske ćelije široko razdvojene obilnim miksoidnim materijalom. Niska celularnost i niska mitotska aktivnost se sreće u najvećem broju slučajeva.Medjutim, većina tumora pokazuje izrazit celularni pleomorfizam. Ukoliko nema nekroze, dijagnoza miksoidnog leiomiosarkoma zahteva difuznu, umerenu do veoma izraženu citološku atipiju i 5 ili više mitoza na 10HPF.

\begin{tabular}{|l|l|l|l|}
\hline Tumorska nekroza & Atipija & MF/10HPF & Dijagnoza \\
\hline Prisutna & Difuzna, umerena do izražena & Bilo kog stepena & leiomiosarkoma \\
\hline prisutna & Nema/laka & $\geq 10$ & Leiomiosarkoma \\
\hline prisutna & Nema/laka & $<10$ & STUMP \\
\hline Nije prisutna & Difuzna, umerena do izražena & $\geq 10$ & Leiomiosarkoma \\
\hline Nije prisutna & Difuzna, umerena do izražena & $<5$ & $\begin{array}{l}\text { Atipični leiomiom sa niskim } \\
\text { stepen rizika ponovnog } \\
\text { javljanja }\end{array}$ \\
\hline Nije prisutna & Difuzna, umerena do izražena & $5-9$ ili atipične mitotske figure & STUMP \\
\hline Nije prisutna & Nema/laka & $<5$ & leiomioma \\
\hline Nije prisutna & Nema/laka & $\geq 5$ & Mitotski aktivan leiomiom \\
\hline Nije prisutna & Fokalna, umerena do izražena & $\geq 5$ & STUMP \\
\hline Nije prisutna & Fokalna, umerena do izražena & $<5$ & Atipični leiomiom \\
\hline
\end{tabular}

Tabela br.4 Histološki kriterijumi za dijagnozu glatko mišićnih tumora 


\section{MEŠOVITI EPITELNI I MEZENHIMNI TUMORI}

\section{Maligni mešoviti Milerov tumor (carcinosarcoma)}

Po definiciji ovaj tumor predstavlja kombinaciju epitelijalne (karcinomske) i mezenhimalne (sarkomske) komponente, sa učestalošću do $10 \%$ svihendometrijalnihmaligniteta ${ }^{9}$. Iako se danas misli da je poreklo obe komponente epitelno (pa zbog toga sarkomski delovi tumora pokazuju pozitivnost i za epitelne i za mezenhimne biomarkere) preduslov za dijagnozu je histološki aspekt mezenhimalne diferencijacije. Tradicionalno se dele na homologi i heterologi tip, što se odredjuje na osnovu diferencijacije sarkomske komponente.

\section{Adenosarkoma}

Mikroskopska slika ${ }^{10}$ : bifazični tumor sa benignom epitelnom i sarkomatoznom - malignom komponentom. Karakteriše se postojanjem kleftova na površini, stromalnog kondenzacijom koja okružuje žlezde i kleftove, a u kojoj se vidi citološka atipija i mitotske figure (više od 1/10HPF). Sarkomska komponenta je najčešće homologi stromalni sarkom niskog stepena maligniteta, ali se ponekad mogu javiti ielementi heterologe diferencijacije na pr. rabdomiomske, hrskavičave...

Diferencijalna dijagnoza uključuje adenofibrom i botrioidni rabdomiosarkom.

\section{Adenofibroma}

Mikroskopska slika: Veoma redak bifazični tumor u kome su benigne i epitelna i mezenhimna komponenta. Površina tumora može biti papilarna, sa kleftovima, ali nema stromalne atipije, mitoza niti periglandularne kondenzacije.

\section{Literatura}

1. Albertini AF, Devouassoux-Shisheboran M, Genestie C. Pathology of endometrioid carcinoma.Bull Cancer. 2012 Jan;99(1):7-12.

2. Silvereberg SG.. Tumors of the uterine corpus:epithelialtumours and related conditions.In: Tavassoli FA, DevileePI,eds. Tumors of the breast and female genital tract. Lyon: WHO; 2003; 2002:218.

3. Lax SF, Kurman RJ, Pizer ES, Wu L, Ronnett BM. A binary archictural grading system for uterin endometrial endometrioid carcinoma has superior reproducibility compared FIGO grading and identifies subsets of advanced -stage tumors with favourable and unfavourable prognosis. Am J SurgPathol 2000; 24: 1201-1208.

4. Lax SF. Precursor lesions of endometrial carcinoma: diagnostic approach and molecular pathology. Pathologe. 2011;32Suppl 2:p.255-64

5. Dionigi A, Oliva E, Clement PB, Young RH. Endometrial stromal nodules and endometrial stromal tumors with limited infiltration:aclinicopathologicstady of 50 cases. Am J surgPathol 2002; 26:567-581.

6. ClementPB.The pathology of the uterine smooth muscle tumors and mixed endometrial stromal-smooth muscle tumors: a selective review with emphasis on recent advances. Int J GynecolPathol 2000; 19:39-55.

7. Hendrickson MR, Tavassoli FA, Kempson RL, et al. Mesenchymal tumorous and related lesions. In: Tavassoli FA, DevileePI,eds.Tumors of the breast and female genital tract. Lyon: IARC Press; 2003; 233-244.

8. Atkins K, Bell S, Kempson RL, Hendrickson MR. Epitheloid smooth muscle tumors of uterus. Mod Pathol 2002; 14(1):132A.

9. RaniKanthan and Jenna-Lynn Senger.Uterine Carcinosarcomas (Malignant Mixed MüllerianTumours): A Review with Special Emphasis on the Controversies in Management. ObstetGynecol Int. 2011; 2011: 470795.

10. Zaloudek CJ, Norris HJ. Adenofibroma and adenosarcoma oh the uterus: a clinicopathologic study of 35 cases. Cancer 1981; 48: 354-366. 